УДК 903.08

https://doi.org/10.24852/2587-6112.2021.6.81.86

\title{
СЕМАНТИКА СЮЖЕТОВ БРОНЗОВОГО БРАСЛЕТА СО СТАРОСЕЛЬСКОГО ТЕРЮХАНСКОГО МОГИЛЬНИКА
}

\author{
(C) 2021 г. К.Н. Втюрина, Е.В. Четвертаков
}

В данной статье рассматривается бронзовый браслет с пятью сюжетными мифологическими вставками, найденный на Старосельском мордовском (терюханском) могильнике. По мнению авторов, данный браслет представляет синтез различных религиозных мотивов: в его мифологических сценах собраны транскультурные архетипы, что свидетельствует об универсальности этих сюжетов, о единстве культурных кодов и о взаимосвязях религиозных преставлений, которые отражены в данном украшении. Рассмотрев все образы, авторы пришли к заключению, что композиция браслета носит неслучайный характер. Главная сцена, она же центральная, дает информацию о мироустройстве, о верховной богине и её ипостасях. С двух сторон её окружают два охранительных образа, представленные в виде животныхстражей - грифонов. По бокам браслета находятся два традиционных образа, видимо, важных для самосознания мордвы-терюхан - «уткоконь» и тотемный барс. Представленная пятичастная система с женским образом в центре встречается довольно часто на различных памятниках искусства во многих культурах.

Ключевые слова: археология, Нижегородская область, Старосельский терюханский могильник, мордва-терюхане, мифологические сцены, бронзовый браслет.

\section{SEMANTICS OF BRONZE BRACELET IMAGES FROM STAROSELSKY TERYUHANSKY CEMETERY}

\author{
K.N. Vtyurina, E.V. Chetvertakov
}

The paper examines a bronze bracelet with five mythological plot inserts, found at the Staroselsky Mordovian (Teryuhansky) cemetery. According to the authors, the bracelet represents a synthesis of various religious motifs: its mythological scenes feature transcultural archetypes, which indicates the universal nature of the plots, the unity of cultural codes and the interrelationships of religious beliefs that are reflected in this adornment. Having considered all the images, the authors came to a conclusion that the composition of the scenes is not random. The main scene, which is also central, provides information about the world order, the supreme goddess and her hypostases. It is surrounded on both sides by two protective images in the form of guardian animals - griffins. On the sides of the bracelet are two traditional images of apparent importance for the selfconsciousness of the Mordvins-Teryukhans - "utkokon" (duck-horse) and totem leopard. The presented fivepart system with a female image in the center is commonly encountered at various art monuments of many cultures.

Keywords: archaeology, Nizhny Novgorod Oblast, Staroselsky Teryuhansky cemetery, Mordva-Teryuhanes, mythological scenes, bronze bracelet.

Старосельский мордовский (терюханский) могильник был впервые обнаружен и обследован археологической экспедицией Дальнеконстантиновского районного музея под руководством Е.В. Четвертакова в 2016 г. (Четвертаков, 2016 , с. 7-20). Памятник расположен на длинном пологом мысу правого коренного берега реки Озерки, правого притока р. Кудьмы, к юго-востоку от окраины застройки деревни Староселье Дальнеконстантиновского района Нижегородской области. Площадь могильника, определенная по области распространения подъемного материала и по особенностям рельефа, равна около 50000 кв. м.
Находки украшений на памятниках мордвы-терюхан, изображающих мифологических существ и животных, немногочисленны. К числу таковых можно отнести несколько артефактов, обнаруженных на Старосельском могильнике в последние годы: бронзовый перстень с изображением барса (Четвертаков, 2020 , с. 34), бронзовый перстень с изображением птицы (Четвертаков, 2019, с. 23), а также серебряный перстень с фигуркой бобра на щитке (Четвертаков, 2019, с. 18). Рассматриваемый в статье бронзовый браслет, украшенный 5 сюжетными мифологическими вставками, дополняет комплекс украше- 
ний с зооморфными образами, а его детальное изучение дает возможность расширить информацию о мировоззрении и погребальном обряде мордвы-терюхан.

Данный браслет был обнаружен в ходе археологических работ на Старосельском терюханском могильнике в 2019 г. в погребении № 32, принадлежащем женщине возрастом 35-40 лет (рис. 1А). С двумя другими бронзовыми пластинчатыми браслетами он был надет на запястье правой руки погребенной (Четвертаков, 2020, с. 18-21).

Кроме упомянутого браслета сопроводительный инвентарь погребения включал в себя: десять застежек-фибул бронзовых с кольцами круглого сечения и с завернутыми перпендикулярно плоскости кольца концами, пять браслетов бронзовых пластинчатых с тупыми концами, украшенных геометрическим орнаментом, шесть подвесок бронзовых полых бубенчиковидных, три привески бронзовые проволочные со стеклянной бисериной, два перстня серебряных, три бусины стеклянных уплощенных, а также бисер стеклянный и шесть раковин каури.

Погребение № 32 относится к погребальной обрядности мордвы-терюхан XVI века и может быть датировано по найденной в сопроводительном детском погребении № 33 серебряной деньге царя Ивана IV (Четвертаков, 2020, с. 21).

Стоит отметить, что в фондах Дальнеконстантиновского районного музея числятся еще 3 фрагмента от бронзовых браслетов, на которых изображены идентичные мифологические сцены. Они были обнаружены на территории Дальнеконстантиновского района и сданы в музей частными лицами. Подобный же браслет опубликован в книге «Ювелирное искусство суваро-булгар - предков чувашей» (Ювенальев, 2018, с. 96, 100), однако место его нахождения неизвестно, что исключает всякую интерпретацию по его происхождению именно от так называемых «суваробулгар».

На территории Нижегородской области, в черте современного города Ардатов, на юговосточной части бывшего с. Тоторшево на мордовском могильнике был найден идентичный антропозооморфный браслет из погребения XVI - середины XVII века (рис. 1Б) (Николаенко, 2004, с. 82).
Н.М. Малкова, автор, который публикует в своей диссертации данный браслет (Малкова, 2000, с. 143), интерпретирует сцены следующим образом:

1. человек на лошади;

2. человек с лошадью (?);

3. медведь;

4. собака (?);

5. пантера (?).

Такой прямолинейный подход кажется авторам статьи весьма ошибочным, автор не только неверно интерпретирует сюжетные сцены браслета, но также искажает сами изобразительные образы. По нашему мнению, данный браслет представляет синтез различных религиозных мотивов: в его мифологических сценах собраны транскультурные архетипы, мотивы которых можно встретить даже в современных произведениях литературы (Пелевин, 2020, с. 301-302), что свидетельствует об универсальности этих сюжетов, о единстве культурных кодов и о взаимосвязях религиозных преставлений, которые отражены в украшении.

\section{Интерпретация сцен}

\section{Сцена 1 (центральная).}

Интерпретацию мифологических сцен следует начать с центральной темы браслета, на которой четко выделяется летящая птица, фигура богини с цветком и существо, напоминающее собаку. Данная сцена иллюстрирует традиционные представления о трёхчастной системе мира, характерные для многих культур. Это не удивительно, так как структура представлений мордвы о строении Вселенной во многом близка представлениям древних индоевропейцев (Девяткина, 1997, с. 92). Для них Вселенная состоит из трех уровней: Небес, Земли и Подземного мира. Символом Верха, посланцами Бога Неба были птицы. Серединный уровень представляла Богиня Мать-Земля, которая символизировала связь жизни и смерти и потому могла возникать в образе хищного зверя, в том числе собаки.

Можно предположить, что образ женщины на центральной сцене связывался мордвойтерюханами со своей верховной богиней, так как здесь имеют место несколько атрибутов (цветок и птица), которые, судя по П.И. Мельникову-Печерскому, автору «Очерков мордвы», принадлежат ей: «Иногда видали богиню на земле то в виде большой птицы с длинным 


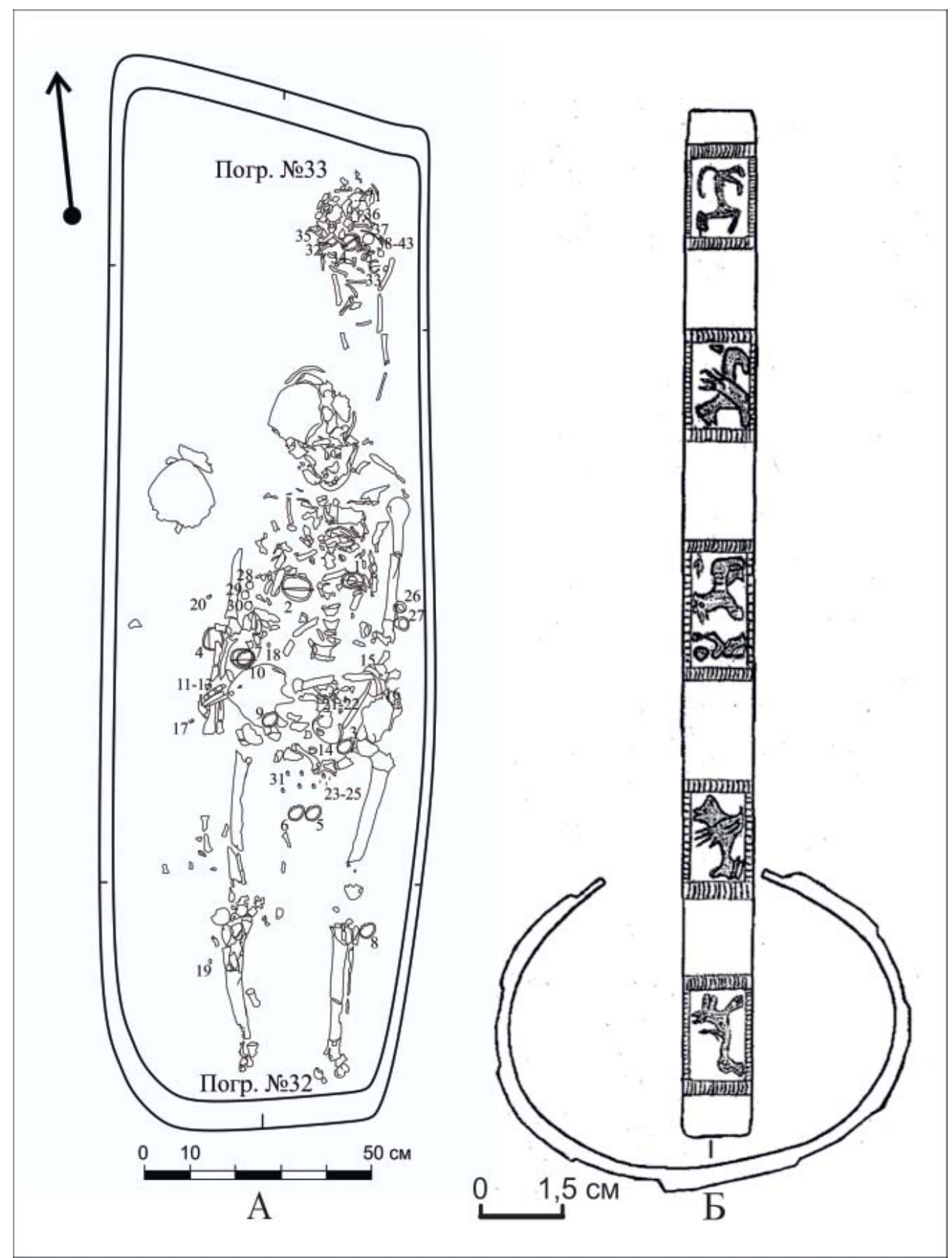

Рис. 1А. Дальнеконстантиновский район. Старосельский терюханский могильник. Погребения №32 и 33 (по Е.В. Четвертакову). Погребение №32: 1-10, 33-35 - застежки-фибулы бронзовые; 11-16 - браслеты бронзовые; 17-22 - подвески бронзовые; 23-25 - привески бронзовые; 26, 27 - перстни серебряные; 28-30 - бусы стеклянные; 31, 38-43 - привески-створки раковин каури ; 32 - браслет железный; 36 - монеты серебряные; 36 - привеска-жетон медный.

1Б. Браслет бронзовый антропо-зооморфный с пятью мифологическими сценами (по Н.М. Малковой).

Fig. 1A. Dalnekonstantinovsky District. Staroselsky Teryukhansky burial ground. Burials Nos. 32 and 33 (after: E. V. Chetvertakov). Burial No. 32: 1-10, 33-35 - bronze fibula clasps; 11-16 - bronze bracelets; 17-22 - bronze pendants; 23-25 - bronze pendants; 26, 27 - silver signet rings; 28-30 - glass beads; 31, 38-43 - cowrie shell pendants; 32 - iron bracelet; 36 - silver coins; 36 - copper pendant-token

15. Anthropo-zoomorphic bronze bracelet with 5 mythological scenes (after: N.M. Malkova)

золотым хвостом..., то в виде белоснежной голубки, которая с высоты кидала иветы пчелам для собирания меда...» (Мельников, 1981, c. 82).
Также в центральной сцене присутствует мифологическое существо с признаками собаки. Есть предположение, что это тоже одна из ипостасей богини-плодородия, та 
сторона богини, которая связана с хтоническим миром. Здесь может иметь место сюжет, в котором богиня, не желая умирать, разделяется на две ипостаси: на свою смерть и на ту, которая не умирает. Образ смерти представлен был в виде собаки (такой сюжет находим в мифологическом цикле богини Иштар, к примеру).

\section{Сцены 2 и 3.}

С двух сторон главную сцену окружают две фантастические твари, которых можно ассоциировать с легко узнаваемым образом грифона. Это существо с головой, когтями, крыльями орла и телом льва. Этот образ пограничный - он символизирует господство над двумя сферами бытия: землей и воздухом (Грифон, 2020). В мифах и легендах разных традиций грифон выступает в роли стража. Он, подобно дракону, охраняет пути к спасению, располагаясь рядом с Древом Жизни либо иным подобным символом. По отношению к нашей композиции грифоны также выступают в роли стражей, защищая главную сцену.

Образ грифона у мордвы довольно плохо изучен. Однако мы с уверенностью можем сказать, что он не был чужд для дохристианской мордвы и был для них легко узнаваем. Самые первые изображения грифона у мордвы мы находим на штампованной серебряной накладке, которая украшала кожаную сумку из погребения № 2 Пановского мордовского могильника VIII-XI веков у деревни Паново Пензенской области. Она дошла до нас в сильно разрушенном состоянии. На ней были изображены три грифона в окружении растительного орнамента (Материальная культура средне-цнинской мордвы VIII-XI вв., 1969, с. 14).

\section{Сцены 4 и 5.}

На концах пластинчатого браслета изображены традиционные образы для мордвы.

На левом крае изображен общий для всех финно-угров образ, часто встречающийся в литературе и искусстве финских народов Поволжья (Рябинин, 1981, с. 55), известный как «конь-птица» (или «уткоконь») - фантастическое существо, совмещающее признаки утки и коня, на котором восседает антропоморф.

У финно-угров конь - символ светлого, радостного, удачливого, а также постоянно обновляющейся природы, это священное животное солнца, а также проводник между миром живых и мертвых, ему приписывали небесное происхождение. Герой может попасть в мифическую страну, устроившись на спине такого существа. На изделиях искусства финно-угров фигура всадника-антропоморфа представлена в различных ипостасях.

На правом конце браслета изображен самый реалистичный образ из всех представленных: угадывается образ большой кошки, скорее всего, барса. Надо сказать, что подобный образ уже был встречен нами в ювелирном искусстве терюхан на перстне из ритуального погребения XIII века со Старосельского терюханского могильника (Четвертаков, 2020, c. 34). По нашему мнению, этот образ был заимствован терюханами в соседней Волжской Булгарии, на территории которой он изображался на бытовых предметах, на глиняных сосудах, в оформлении замков (Город Болгар: культура, искусство, торговля; 2008, с. 213-215), также известны случаи использования барсов в качестве тотемов. Не исключено, что такое же значение данный образ имел для мордвы-терюхан.

Рассмотрев все образы, мы понимаем, что композиция расположения не случайна. Во-первых, главная сцена, она же центральная, дает информацию о мироустройстве, о верховной богине и её ипостасях. С двух сторон её окружают два охранительных образа, представленных в виде животныхстражей грифонов. По бокам браслета два традиционных образа, видимо, важных для самосознания мордвы-терюхан - «уткоконь» и тотемный барс. Такая пятичастная система с женским образом в центре встречается довольно часто на различных памятниках искусства во многих культурах.

\section{ЛИТЕРАТУРА}

Город Болгар: культура, искусство, торговля / отв. ред. П. Н. Старостин. М.: Наука, 2008. 276 с.

Грифон // Энциклопедия вымышленных существ URL: https://www.bestiary.us/grifon/ru (дата обращения: 21.10.2020).

Девяткина Т.П. Мифология мордвы (традиционная картина мира и образ мышления) // Вестник мордовского университета. 1997. № 2-3. С. 92-97. 
Малкова H.M. Погребальный обряд и инвентарь могильников эрзи и мокши XVI - начала XIX вв. дисс. ... канд. ист. наук. Самара, 2000. 330 с.

Материальная культура Средне-Цнинской мордвы VIII-XI вв. / Отв. ред. А.П. Смирнов. Саранск: Мордов. кн. изд-во, 1969. 176 с.

Николаенко Т.Д. Археологическая карта России. Нижегородская область. Ч. 1. М.: ИА РАН. 2004. $384 \mathrm{c}$.

Пелевин В. Generation "П". СПб.: Азбука-Аттикус, 2020. 320 с.

Мельников-Печерский П.И. (Андрей Печерский). Очерки Мордвы. Саранск: Мордовское книжное издательство, 1981. 132 с.

Рябинин Е.А. Зооморфные украшения Древней Руси X-XIV вв. / САИ. Е1-60. Л.: Наука, 1981. 144 с.

Четвертаков Е.В. Отчет об археологической разведке на территории Дальнеконстантиновского и Краснобаковского районов Нижегородской области в 2016 году // Архив ИА РАН. Р-1. 151 с.

Четвертаков E.B. Отчет об археологических раскопках на могильнике Староселье 3 в Дальнеконстантиновском районе Нижегородской области в 2018 году // Архив ИА РАН. Р-1. 2020. 140 с.

Четвертаков Е.В. Отчет об археологических раскопках на могильнике Староселье 3 в Дальнеконстантиновском районе Нижегородской области в 2018 году // Архив ИА РАН. Р-1. 2019. 132 с.

Ювенальев Ю. Ювелирное искусство суваро-булгар - предков чувашей. Чебоксары: Чувашское книжное изд-во, 2018. $126 \mathrm{c.}$

\section{Информация об авторах:}

Втюрина Ксения Николаевна, Нижегородский государственный университет им. Лобачевского, ИМОМИ (г. Нижний Новгород, Россия); kvtyurina@inbox.ru

Четвертаков Евгений Валентинович, методист, Дальнеконстантиновский районный музей (г. Нижний Новгород, Россия); Tank_kuz@mail.ru

\section{REFERENCES}

In Starostin, P. N. (ed.). 2008. Gorod Bolgar. Kul'tura, iskusstvo, torgovlia (City of Bolgar. культура, искусство, торговля). Moscow: "Nauka" Publ. (in Russian).

Griffin. Available at: https://www.bestiary.us/grifon/ru (accessed: 21.10.2020) (in Russian).

Deviatkina, T. P. 1997. In Vestnik mordovskogo universiteta (Bulletin of Mordovian University) 2-3, 92-97 (in Russian).

In Starostin, P. N. (ed.). 2008. Gorod Bolgar. Kul'tura, iskusstvo, torgovlia (City of Bolgar. Culture, Art, Trade). Moscow: "Nauka" Publ. (in Russian).

Smirnov, A. P. (ed.). 1969. Material'naia kul'tura Sredne-Tsninskoi mordvy VIII-XI vv. (Material Culture of the Mordva People on the Middle Tsna River in $8^{\text {th }}-10^{\text {th }}$ Centuries). Saransk: "Mordovskoe knizhnoe izdatel'stvo" Publ. (in Russian).

Nikolaenko, T. D. 2004. Arkheologicheskaia karta Rossii. Nizhegorodskaia oblast' (Archaeological Map of Russia. Nizhny Novgorod Region). Part 1. Moscow: Institute of Archaeology, Russian Academy of Sciences (in Russian).

Pelevin, V. 2020. Generation "P". Saint Petersburg: "Azbuka-Attikus: Publ. (in Russian).

Mel'nikov-Pecherskiy, P. I. (Andei Pecherskiy). 1981. Ocherki Mordvy (Essays on the Mordva). Saransk: "Mordovskoe knizhnoe izdatel'stvo" Publ. (in Russian).

Ryabinin, E. A. Zoomorfnye ukrasheniya Drevney Rusi X-XIV vv. (Zoomorphic Adornments in Ancient Rus of $10^{\text {th }}-14^{\text {th }}$ Centuries). Series: Svod Arkheologicheskikh Istochnikov (Corpus of Archaeological Sources) E1-60. Leningrad: "Nauka" Publ. (in Russian).

Chetvertakov, E. V. 2016. Otchet ob arkheologicheskikh razvedkakh na territorii Dal nekonstantinovskogo I Krasnobakovskogo rajonov Nizhegorodskoj oblasti v 2016 godu. (Report on Archaeological Exploration in the Territory of the Dalnekonstantinovsky and Krasnobakovsky Districts of the Nizhny Novgorod Oblast in 2016). Archive of the Institute of Archaeology of the Russian Academy of Sciences R-1 (in Russian).

Chetvertakov, E. V. 2019. Otchet ob arkheologicheskikh raskopkakh na mogil'nike Starosel'e $3 v$ Dal nekonstantinovskom rajone Nizhegorodskoj oblastiv 2018 godu. (Report on Archaeological Excavations at Staroselie 3 burial ground in the Dalnekonstantinovsky District of the Nizhny Novgorod Oblast in 2018). Archive of the Institute of Archaeology of the Russian Academy of Sciences R-1 (in Russian).

Chetvertakov, E. V. 2020. Otchet ob arkheologicheskikh raskopkakh na mogil'nike Starosel'e $3 v$ Dal nekonstantinovskom rajone Nizhegorodskoj oblasti v 2019 godu. (Report on Archaeological Excavations at Staroselie 3 burial ground in the Dalnekonstantinovsky District of the Nizhny Novgorod Oblast in 2019). Archive of the Institute of Archaeology of the Russian Academy of Sciences R-1 (in Russian). 
Yuvenal'ev, Yu. 2018. Iuvelirnoe iskusstvo suvaro-bulgar - predkov chuvashei (Jewelry Art of the SuvarBolgars - the Ancestors of the Chuvash). Cheboksary: "Chuvashskoe knizhnoe izdanie" Publ. (in Russian).

\section{About the Authors:}

Vtyurina Ksenia N. N. I. Lobachevsky State University of Nizhny Novgorod. Gagarin Ave., 23, Nizhny Novgorod, 603950, Russian Federation; kvtyurina@inbox.ru

Chetvertakov Eugeny V. Dalnekonstantinovsky District Museum. Sovetskaya St., 89, Nizhny Novgorod, 606310, Russian Federation; Tank_kuz@mail.ru

Статья поступила в журнал 01.10.2021 г. Статья принята к публикации 01.12.2021 г. Авторы внесли равноценный вклад в работу. 